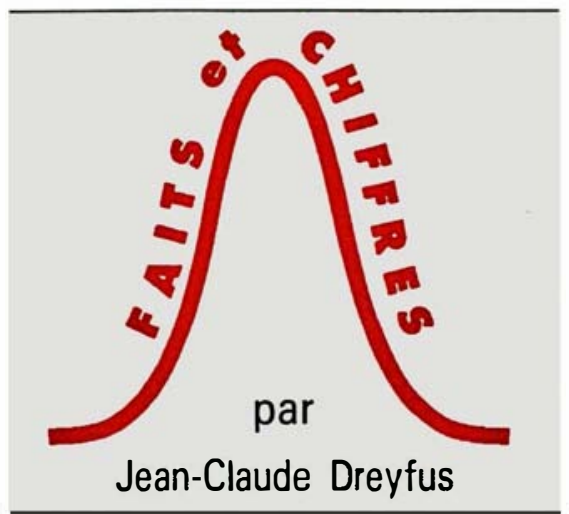

\title{
La population de la France après le recensement de 1990
}

$\mathbf{L}$ es dernières données démographiques françaises publiées par $\mathrm{m} / \mathrm{s}$ l'ont été en mai 1990 ( ${ }^{\circ}$ 5, vol. 6, p. 478) avant le recensement de cette même année. On dispose maintenant, après ce recensement, de chiffres rectifiés, incluant 1991, parus dans Population et Societés sous le titre "De 54 à 57 millions d'habitants ", le premier chiffre étant celui de 1980 [1]. En 11 ans donc, la population française s'est accrue de trois millions. Cette augmentation, proche de 300000 par an, se poursuit malgré la diminution de la ferti- lité. Les données actuelles sont figurées sur la figure 1 [2] et le Tableau I. En comparant avec les valeurs publiées il y a deux ans, on observe une réévaluation de 275000 personnes, consécutive au recensement. L'examen du Tableau I permet de reconnaître ce qui revient à l'excédent naturel et au solde migratoire, ce dernier gardant une certaine approximation. On y trouve aussi les taux de natalité, de fertilité, de mortalité, tous lentement régressifs, et l'espérance de vie, grignotant chaque année quelques mois. Enfin le

Tableau I

FRANCE MÉTROPOLITAINE : INDICATEURS DÉMOGRAPHIQUES 1982-1991

\begin{tabular}{|l|c|c|c|c|c|c|c|c|c|c|}
\hline & 1982 & 1983 & 1984 & 1985 & 1986 & 1987 & 1988 & 1989 & 1990 & 1991 (p) \\
\hline Naissances (m) & 792 & 749 & 760 & 768 & 778 & 768 & 771 & 765 & 762 & 759 \\
Décés (m) & 543 & 560 & 542 & 552 & 547 & 527 & 525 & 529 & 526 & 526 \\
Excédent naturel (m) & 254 & 89 & 217 & 216 & 232 & 240 & 247 & 236 & 236 & 233 \\
Solde migratoire (m) & 61 & 56 & 45 & 38 & 39 & 44 & 57 & 71 & 80 & 80 \\
Variation totale (m) & 315 & 245 & 262 & 254 & 271 & 284 & 304 & 307 & 316 & 313 \\
\hline $\begin{array}{l}\text { Taux de natalité (t) } \\
\text { Taux de mortalité (t) }\end{array}$ & 14,6 & 13,7 & 13,8 & 13,9 & 14,0 & 13,8 & 13,7 & 13,6 & 13,4 & 13,3 \\
Taux de mortalité & 10,0 & 10,2 & 9,9 & 10,0 & 9,8 & 9,4 & 9,3 & 9,4 & 9,3 & 9,2 \\
infantile (r) & 9,5 & 9,1 & 8,3 & 8,3 & 8,0 & 7,8 & 7,8 & 7,5 & 7,3 & 7,3 \\
\hline $\begin{array}{l}\text { Indice de fécondité (e) } \\
\text { Espérance de vie }\end{array}$ & 1,91 & 1,78 & 1,80 & 1,81 & 1,83 & 1,80 & 1,80 & 1,79 & 1,78 & 1,77 \\
$\quad$ hommes (a) \\
femmes (a)
\end{tabular}

(a) années; (p) provisoire; (1) en fin d'année; (e) enfants pour une femme; ( $r$ ) taux pour 1000 naissances vivantes; (m) milliers ; ( $t$ ) taux pour 1000 habitants. 
Tableau II montre les principales variations entre les recensements successifs de 1962 à 1990 [3].

Parmi les indicateurs qui ne figurent pas dans les Tableaux, mentionnons la nuptialité, en légère baisse après une remontée modérée (281000 mariages en 1991 contre 287000 en 1990 et 265000 en 1987) ; les naissances hors mariage atteignent $30 \%$ du total contre $11,4 \%$ en 1980 et $6 \%$ en 1960. D'où, puisque le nombre total des naissances reste stable, une baisse des naissances "légitimes "; parmi celles-ci, le pourcentage de naissances issues de deux parents français est de 85.

Si l'on constate qu'il a fallu 11 ans pour que la France passe de 54 à 57 millions d'habitants, peut-on extrapoler pour l'avenir, même en admettant que ne surviennent pas de grands remaniements politiques ou migratoires? Malgré une fécondité basse, qui n'assure pas, on le sait, le renouvellement des générations pour l'avenir, l'excédent naturel reste garanti pour plusieurs années. La France pourrait donc atteindre 60 millions d'habitants dans les premières années du XXIe siècle. Une telle perspective table sur un solde migratoire constant ou peu modifié, ce qui n'a, bien entendu, rien d'assuré. Il reste que ce solde démographique positif contraste avec la situation de la plupart des pays voisins de taille comparable, à l'exception sans doute de la Grande-Bretagne

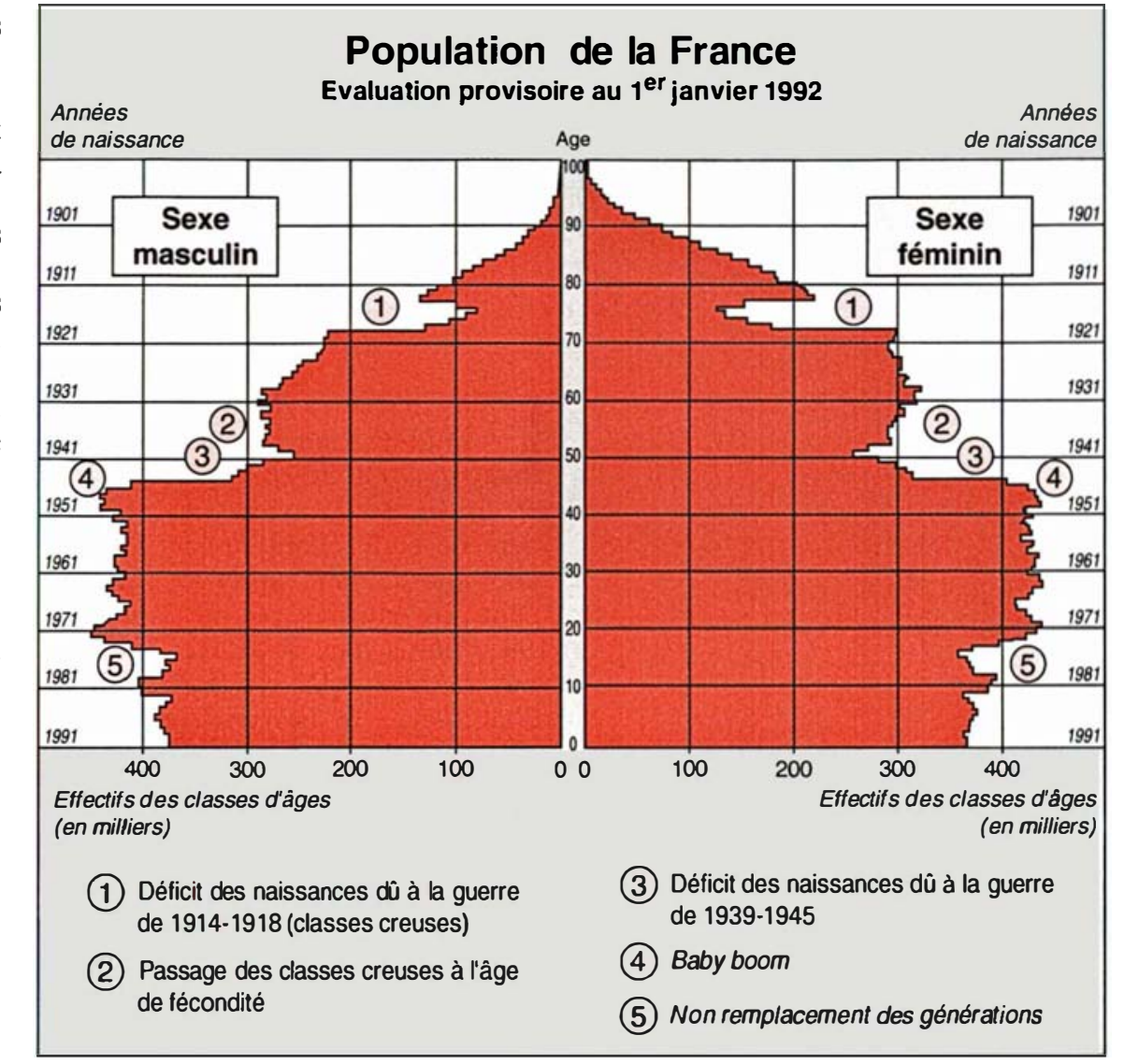

Figure 1. Pyramides des âges de la France au 1 or janvier 1992. (Source

INSEE [2].)

\begin{tabular}{|c|c|c|c|c|}
\hline \multicolumn{5}{|c|}{$\begin{array}{l}\text { Tableau II } \\
\text { E MÉTROPOLITAINE. } \\
\text { CENSITAIRES DE LA POPULATION } \\
\text { ENNES ANNUELLES) }\end{array}$} \\
\hline & $\begin{array}{c}1962 \\
\mathrm{a} \\
1968\end{array}$ & $\begin{array}{c}1968 \\
a \\
1975\end{array}$ & $\begin{array}{c}1975 \\
a \\
1982\end{array}$ & $\begin{array}{c}1982 \\
a \\
1990\end{array}$ \\
\hline $\begin{array}{l}\text { Accroissement annuel (milliers) } \\
\text { Excédent naturel (milliers) } \\
\text { Solde }{ }^{*} \text { (milliers) } \\
\text { Taux d'accroissement total } \\
\text { (\% par an) dont : } \\
\text { excédent naturel (\% par an) } \\
\text { solde* (\% par an) }\end{array}$ & $\begin{array}{r}549 \\
319 \\
230 \\
1,15 \\
\\
0,68 \\
0,47\end{array}$ & $\begin{array}{r}413 \\
295 \\
118 \\
0,81 \\
0,58 \\
0,23\end{array}$ & $\begin{array}{r}248 \\
211 \\
37 \\
0,46 \\
0,40 \\
0,07\end{array}$ & $\begin{array}{r}279 \\
228 \\
51 \\
0,50 \\
0,41 \\
0,09\end{array}$ \\
\hline
\end{tabular}

\section{Source INSEE [3]}

* Ce solde résulte à la fois de l'excédent migratoire et d'éventuelles différences de prócision entre recensements.

INTERCENSITAIRES DE LA POPULATION (MOYENNES ANNUELLES
1. Lévy ML. De 54 à 57 millions d'habitants. Population el Sociétés, INED (Institut national d'études démographiques), mars 1992, n² 266. 2. Bilan démographique 1991. Bull Mens Statist, INSEE, janvier 1992, 95-101.

. Recensemement de la population de 1990. Source : Calot G. La fécondité en Europe analogies et différences. Population et Sociétés. INED (Institut national d'études démographiques), janvier 1992, nº 264. 